\title{
Understanding Learners' Satisfaction in Blended Learning among Undergraduate Students in Malaysia
}

\author{
Umi Kalsom Masrom ${ }^{1, *}$, Nik Aloesnita Nik Mohd Alwi ${ }^{2}$, Nor Hazlin Nor Asshidin ${ }^{1}$ \\ ${ }^{1}$ College of Business Management and Accounting, Energy University, Malaysia \\ ${ }^{2}$ Centre for Modern Languages, Universiti Malaysia Pahang, Malaysia
}

Received June 28, 2019; Revised August 21, 2019; Accepted September 5, 2019

Copyright $\mathrm{C} 2019$ by authors, all rights reserved. Authors agree that this article remains permanently open access under the terms of the Creative Commons Attribution License 4.0 International License

\begin{abstract}
Blended learning has extensively been used in many higher education institutions including Malaysia. Hence, instructors and institutions need to be well-equipped with adequate knowledge and skills, so that blended learning could be implemented successfully. This paper investigates the satisfaction among learners in blended learning environment at one of the universities in Malaysia through a survey study. The participants were 317 undergraduates enrolled in a blended learning course. The questionnaire was adapted from Zhai, Gu, Liu, Liang and Chin-Chung (2017) and Naaj, Nachouki and Ankit (2012). Descriptive statistics was employed to analyze the learners' demographic and their satisfaction towards blended learning. The results indicate that the learners' satisfaction towards blended learning employed at their institution was positive. This study also highlights several implications and recommendations that could anchor a greater understanding in the implementation of blended learning at higher institutions.
\end{abstract}

Keywords Blended Learning, Learner Satisfaction, Undergraduate Students, Higher Education Institutions

\section{Introduction}

The use of technology in the learning and teaching process has been employed by practitioners and classroom instructors around the world including Malaysia. For example, in Malaysia, many education institutions particularly at a tertiary level have implemented blended learning, which is the combination of online learning and face-to-face interaction. It has considerably been accepted as one of the approaches in learning and teaching by the instructors and learners. According to [11], the application of blended learning has become prevalent in higher education institutions and could be considered as an essential element in education. Following advances and extensive, active use of blended learning in Malaysia higher education institutions, there is a need to examine the extent of the current state of blended learning implementation. This is particularly important in order to examine its potential in promoting quality education similar to what the traditional learning can offer. Prior studies typically focused on course components and found positive effects on students' learning. Meanwhile, a few have mentioned the need to consider learners' satisfaction in relation to their learning experiences in blended learning [19]. Understanding learner satisfaction is important to complement course components so as a more conducive blended learning environment can be created. As such, the current study intends to provide further insights into learner satisfaction towards blended learning in an attempt to provide guidelines and workable recommendation for the practitioners and institutions that inspire to make a full use of blended learning as part of the learning and teaching processes.

\section{Learner Satisfaction in Blended Learning}

Several studies have explored the extent of learners' satisfaction in the ever dynamic and sophisticated blended learning atmosphere. For example, [18] conducted a study to explore the predictors of satisfaction among university students in Taiwan. Data were collected using snowball and convenient sampling techniques, in which two hundred and twelve $(n=212)$ students provided responses on 21 items. Based on the structural equation modelling approach, the results showed that social environment, technological environment and cognitive factor affect satisfaction in the blended learning environment. The study concluded that the interaction of these three elements affects satisfaction as a whole and not in isolation. 
Meanwhile, in an earlier study, [15] investigated the factors that affect learner satisfaction in an e-learning context. The results from the regression analysis demonstrated several factors affecting learners which were computer anxiety, instructor attitude toward e-learning, the flexibility and quality of the course, perceived usefulness, perceived ease of use and variety in assessments. These seven dimensions were believed to be needed to maintain students' motivation that could warrant a fruitful e-learning implementation in distance education.

A review of literature was performed by [13] for studies published from 2014 to 2017. Forty-four peer reviewed articles were examined in a search of the factors that affect e-learning and blended learning in terms of learning outcomes, engagement and satisfaction. It was found that some factors such as educator existence in online settings, student interaction, teachers and content, and deliberate acquaintances between online and offline activities and between campus-related and practice-related activities could give more influence compared to other factors.

In a study among university students in Ajman University of Science Technology in United Arab Emirates, [12] examined students' satisfaction in a blended learning environment. In order to gauge students' perceived satisfaction on the course, Student Satisfaction Survey Form (SSSF) with 35 items was employed. The instrument includes five constructs namely interaction (9 items), instruction (12 items), instructor (5 items), course management (3 items) and technology (6 items). Interaction is believed to promote collaboration and immediate feedback. Instruction refers to the coaching learners received in the course they were enrolled in while instructor is the one who gives the instruction during the teaching and learning process. Course management includes administrative support and access to learning resources while technology refers to the access to the use of reliable equipment that was used in learning. All of these five variables were seen as important elements of learner satisfaction. A total of 108 responses were received from the participants. The findings revealed that the overall satisfaction of the students was higher than the average. In addition, the study also distinguished the satisfaction among male and female students; and found that male students were more likely to be satisfied than the female students. This could be because female students prefer face-to-face setting whereby they have more contact and discussion with their instructors.

Prior research concerning improving learner satisfaction has indicated that blended learning not only can increase student satisfaction, but also give positive effect on students' understanding and consequently increase students' academic performance [1]. Furthermore, [5] has contended that instructors need to provide more support to learners and make use of an online platform that is homogenous and user-friendly so that blended learning could be successfully sustained. To address student satisfaction in blended and online courses among university students, [4] proposed instructors to be alert of the role of learners' personality in the selection of course modality. Moreover, [6] recommended the role of psychological aspects in defining student satisfaction in online learning. In relation to the online platforms, a study found that learners were satisfied with various platforms such as Edmodo [3] and WhatsApp [7] in support of their learning condition.

With the concerns and satisfaction in flipped and blended learning environments, [8] searched for empirical evidences of learner outcomes, performance and satisfaction. The results from the path model analysis showed that both learning environments could give positive impact on learners' perception on satisfaction, engagement and performance. The finding also concluded that engagement in a flipped learning could stimulate more intrinsic satisfaction among learners regardless of their perception on performance.

In the context of a flipped classroom, [19] carried out a longitudinal survey study to recognize students' satisfaction among 178 undergraduates in China. Using an experiential learning theory, the study focused on five variables such as perceived quality, personalized learning climate, prior learning experience, perceived value and overall satisfaction. Perceived quality in the study consisted of five components namely ease of using the online course, usefulness of the online course, ease of using the platform, usefulness of the platform and interaction in physical classes. Personalized learning climate refers to the learning context whereby learners can adjust their own learning pace while prior learning experience was derived from learners' frequency of participation and preference. Next, perceived value was defined as "perceived assessment of how much received versus cost" (p.201). Finally, overall satisfaction caters general learner satisfaction in a flipped classroom context. The results showed that personalized learning climate and prior learning experience were the most important components of students' satisfaction. The study claimed that these two variables are essential because they allowed learners to work at their own pace while learning.

A recent meta-analysis study conducted by [17] compared flipped classrooms and non-flipped classrooms conditions. The study analyzed 114 studies and contended that there was no evidence that flipped classrooms had a significant effect on student satisfaction. Nevertheless, in terms of achievement, they found that students performed significantly better in a condition where flipped classrooms have more face-to-face interaction.

Despite of identifying factors that could directly impact learner satisfaction, some research have recently identified readiness as an important variable dealing with learner satisfaction. Among them, the finding by [16] had contributed to the understanding of learner satisfaction to some extent. The regression model analysis demonstrated 
that five constructs of learner readiness; performance expectation, self-directed learning, online communication self-efficacy, learner control and motivation for learning; were the important aspects in influencing learner satisfaction.

Blended learning can be challenging due to numerous factors that could influence the efficiency of its implementation. A deep understanding of what may influence learners to learn and how best they could learn in the blended learning environment are two important variables for instructors to put emphasis on so that a conducive environment that suits learners' need could be created, and eventually promote greater learner satisfaction alongside the pedagogically valuable manner. As reviewed in the literature, further studies should be conducted for a more comprehensive understanding of factors that could affect learner satisfaction as they experience learning and teaching process in a blended learning setting.

\section{Methodology}

This study applies a quantitative design by means of a survey. Survey is commonly used for data collection purpose in education research, because it allows researcher to measure participants' attitudes and opinions toward some issues [2]. An online survey was used in this study, because it allows researcher to collect opinions among students from different programs of study which involved two campuses.

\subsection{Instrument}

In determining the instrument for this study, a number of studies were reviewed in order to warrant a wide-ranging list of measures to be included. All measures for each construct were adapted from previously validated instruments and adjusted based on the context of the study. For example, the measures of perceived quality, personalized learning climate, prior learning experience and perceived value were adapted from [19] while the measures for interaction, instruction, instructor, course management, technology and overall satisfaction were taken from [12].

The instrument includes two sections. The first section (Section A) aims to collect demographic details of the learners, while the second section (Section B) assesses learner satisfaction towards blended learning. Three hundred seventeen ( $\mathrm{N}=317)$ learners who were enrolled in various courses employing blended learning participated in this study. The data was collected through an online survey at one of the private, Government-Linked Universities (GLU) in Malaysia. The instrument consisted of 60 items using a 4-point Likert scale ranging from strongly disagree to strongly agree. The analyses were conducted using
Statistical Package for Social Sciences (SPSS) version 21.0 software.

\section{Results and Discussion}

\subsection{Section A}

The purpose of this study is to determine the satisfaction towards the implementation of blended learning among tertiary level learners. Getting to know the demographic information might be necessary so that comparison in terms of participants' characteristics can be made in future studies. Similar findings might be observed in a blended learning setting where participants' characteristics are similar with the current study. Gender, age group, level of study, academic performance and computer literacy are among these traits. In the first section, participants are asked to fill in the demographic information. Table 1 shows the demographic information of the participants. The demographic data include students' gender, age, level of study, Cumulative Grade Point Average (CGPA) and computer literacy.

Table 1. Demographic Characteristics of Participants

\begin{tabular}{|c|c|c|}
\hline Information & $\mathrm{N}$ & Frequency \\
\hline $\begin{array}{c}\text { Gender } \\
\text { Male } \\
\text { Female }\end{array}$ & $\begin{array}{l}114 \\
203\end{array}$ & $\begin{array}{l}35.96 \\
64.04\end{array}$ \\
\hline $\begin{array}{c}\text { Age } \\
18-19 \\
20-21 \\
22-23 \\
24-25\end{array}$ & $\begin{array}{c}34 \\
191 \\
81 \\
11 \\
\end{array}$ & $\begin{array}{c}10.73 \\
60.25 \\
25.55 \\
3.47\end{array}$ \\
\hline $\begin{array}{c}\text { Level of study } \\
\text { Foundation } \\
\text { Diploma } \\
\text { Bachelor }\end{array}$ & $\begin{array}{c}8 \\
48 \\
261\end{array}$ & $\begin{array}{c}2.52 \\
15.14 \\
82.33\end{array}$ \\
\hline 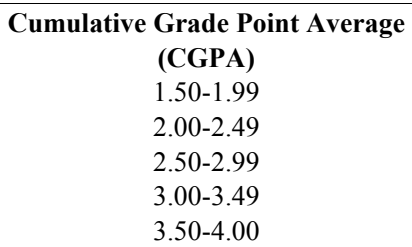 & $\begin{array}{c}1 \\
23 \\
50 \\
116 \\
110\end{array}$ & $\begin{array}{c}0.32 \\
7.26 \\
15.77 \\
36.59 \\
34.70\end{array}$ \\
\hline $\begin{array}{c}\text { Computer literacy } \\
\text { No experience } \\
\text { Novice } \\
\text { Intermediate } \\
\text { Expert }\end{array}$ & $\begin{array}{c}13 \\
100 \\
174 \\
30\end{array}$ & $\begin{array}{c}4.10 \\
31.55 \\
54.89 \\
9.5\end{array}$ \\
\hline
\end{tabular}

In Section A, participants are also asked to provide information on their familiarity to various blended learning applications. This is to gain further insights on the platforms that the learners were exposed to during their study period. The summary of learners' exposure to various online applications in a blended learning context is presented in Table 2. 
Table 2. Learners Exposure to Blended Learning Applications

\begin{tabular}{|c|c|c|}
\hline Applications & Frequency (\%) & Frequency (\%) \\
\hline & Yes & No \\
\hline Answer Pad & 1.89 & 98.1 \\
\hline Screencast-O-Matic & 0.63 & 99.37 \\
\hline Ed Puzzle & 7.26 & 92.73 \\
\hline Edmodo & 9.78 & 90.22 \\
\hline Explain & 2.84 & 97.16 \\
\hline Go Class & 0.95 & 99.05 \\
\hline Kahoot & 53.94 & 46.06 \\
\hline Khan Academy & 0.31 & 99.69 \\
\hline Moodle & 80.44 & 19.56 \\
\hline Padlet & 42.59 & 57.41 \\
\hline Wiki & 8.2 & 91.8 \\
\hline You Tube & 37.54 & 62.46 \\
\hline
\end{tabular}

The results indicated that the highest frequency of application used was Moodle (80.44\%), followed by Kahoot (53.94\%) and Padlet (42.59\%). On the other hand, the least used application was Khan Academy (0.31\%), Screencast-O-Matic (0.63\%) and Go Class (0.95\%).

In the second section, students were given 60 instances of satisfaction on 10 dimensions.

\subsection{Section B}

The results of section B are summarized in Table 3 .

Table 3. Descriptive Statistics for Learner Satisfaction Dimensions $(\mathrm{N}=317)$

\begin{tabular}{|c|c|c|c|c|}
\hline $\begin{array}{c}\text { Sub-categories of Learner } \\
\text { Satisfaction }\end{array}$ & Mean & Median & Mode & SD \\
\hline Perceived quality & 3.03 & 3 & 3 & 0.497 \\
\hline $\begin{array}{c}\text { Personalized learning } \\
\text { climate }\end{array}$ & 3.05 & 3 & 3 & 0.466 \\
\hline Prior learning experience & 2.97 & 3 & 3 & 0.552 \\
\hline Perceived value & 3.01 & 3 & 3 & 0.534 \\
\hline Interaction & 2.80 & 2.75 & 3 & 0.286 \\
\hline Instruction & 2.78 & 2.75 & 3 & 0.261 \\
\hline Instructor & 2.90 & 2.80 & 3 & 0.319 \\
\hline Course management & 3.09 & 3 & 3 & 0.531 \\
\hline Technology & 3.06 & 3 & 3 & 0.451 \\
\hline Overall satisfaction & 3.12 & 3 & 3 & 0.473 \\
\hline
\end{tabular}

Table 3 presents the descriptive statistics (mean, median, mode, standard deviation) of satisfaction variables towards blended learning. The suitable central tendency for this data is median, because the data are all categorical variables. Based on Table 3, the median for all sub-categories of learner readiness is 3.0. This indicates that majority of the learners were in an agreement with the items in the questionnaire (Section B). Most of the value of standard deviation (SD) is around 0.5 , which specifies that the data are not too scattered. A few values fall from 0.26 to
0.32 which indicates that the data fall a bit far from the central tendency.

The findings highlight two important points. Firstly, students were generally satisfied with all of the components of learner satisfaction. This provides support to the previous studies [12] and [19]. Secondly, there were three sub-categories in which students were less in an agreement with; namely interaction, instruction and instructor. The three sub-categories are connected to the role of instructors in a blended learning environment, and perhaps students were less satisfied with the instructors' role in providing instruction and mediating interaction during teaching and learning process. According to [14], it is the instructors' role to understand what and how learners learn so that the course could be designed according to the learners' need. Furthermore, [18] made suggestion to instructors to actively motivate learners to participate in the classroom interaction and to provide feedback in order to enhance more engagement and satisfaction among learners.

Moreover, less satisfaction with the interaction could be due to the learners' individual characteristics. [4] proposed that learners' individual traits can regulate the degree of their interaction and participation in learning. Hence, the instructors should be aware of such traits in the learners so that they can guide the learners with low self- confidence to build trust in themselves and finally to develop their self-efficacy.

Likewise, in an online learning environment, it is also important to design effective courses so that it could promote quality learning and satisfaction [9]. The shortcomings in developing effective course design could probably lead learners to have less satisfaction with the instructors and instructions. Similarly, [10] noted that the course design features such as clear assignment guidance, the instructors' feedback and the instructors' knowledge of the course content were closely related to the course satisfaction.

In summary, the results revealed that learners have less satisfaction in terms of interaction, instructor and instruction. This is probably because the instructors may have insufficient knowledge and skills in implementing blended learning. When the study was conceived, the implementation of blended learning in the institution was at the initial stage. The results suggest that the instructors must encourage and motivate learners to engage in more interaction which is either via face-to-face or the online setting. In addition, the instructors could also plan and design more collaborative work so that learners can have more opportunity for interaction through online correspondence which allows them to track their progress or performance on the online platforms. Finally, throughout the process of teaching and learning, the instructors could also offer consistent scaffolding so that learners are willing to interact because they know how to interact and, consequently foster active interaction not only 
among the students themselves but also with the instructors.

\section{Implications and Conclusions}

The current study reports the findings on learner satisfaction in a blended learning context at one of the private, GL universities in Malaysia. Therefore, the results should not be overgeneralized to other context as it may not be applicable to different settings.

Although the current study provides comparable understanding of learner satisfaction in a blended learning environment, it somehow manages to demonstrate a more detailed view of aspects influencing learner satisfaction in a blended learning context at a tertiary level. More importantly, the current study draws attention to several implications. Firstly, practitioners in higher learning institutions are advised to consider various factors including those described in the findings, related to satisfaction. Other variables such as perceived quality, personalized learning climate, prior learning experience, perceived value, interaction, instruction, instructor, course management and technology need to also be taken into account when designing blended learning courses. This is to encourage students to have a greater satisfaction and eventually increase students' performance. Moreover, institutions could model after the empirical evidence in order to enhance facilities that may assist in creating personalized learning experiences for the students.

Although this study has provided empirical evidence in understanding the construct of learner satisfaction in blended learning atmosphere, the results should not be overgeneralized to other perspective as it may not be appropriate to different context as mentioned earlier. The concept of blended learning is not new. Similar to other teaching and learning approaches, its implementation is just getting better as fascinatingly complex digital undergraduates continue to enroll in higher education institutions. Thus, the practitioners should constantly review, innovate, and improve its implementation for our students to reap the benefits.

\section{Acknowledgements}

The authors express their warm appreciation for the financial support provided by the Energy University under the BOLD2025 Grant (10436494/B/2019064).

\section{REFERENCES}

[1] Anaraki, F. (2018). The effectiveness of blended learning: a case study. ABAC Journal, 38(2), 82-93.
[2] Ary, D., Jacobs, L.C., Razavieh, A. \& Sorensen, C. (2006). Introduction to Research in Education. 7th Ed. Thomson Wadsworth. Canada.

[3] Ateş Çobanoğlu, A. (2018). Student teachers' satisfaction for blended learning via Edmodo learning management system. Behaviour \& Information Technology, 37(2), 133-144.

[4] Bolliger, D. U., \& Erichsen, E. A. (2013). Student satisfaction with blended and online courses based on personality type. Canadian Journal of Learning and Technology, 39(1), 1-23.

[5] Botha, J. (2019). Student satisfaction with a blended learning approach: implementation evaluation of three Honours programmes in Education. Master theses. Stellenbosch: Stellenbosch University.

[6] Dziuban, C., Moskal, P., Thompson, J., Kramer, L., DeCantis, G., \& Hermsdorfer, A. (2015). Student satisfaction with online learning: Is it a psychological contract? Online Learning, 19(2), 122-136.

[7] Ismail, A. M. A. (2018). Empowering your students' satisfaction with Blended Learning: A lesson from the Arabian Gulf University Distance Teaching and Training Program. International Journal of Information and Education Technology, 8(2), 108-120.

[8] Fisher, R., Perényi, Á., \& Birdthistle, N. (2018). The positive relationship between flipped and blended learning and student engagement, performance and satisfaction. Active Learning in Higher Education, 00(0), 1-17.

[9] Gray, J. A., \& DiLoreto, M. (2016). The effects of student engagement, student satisfaction, and perceived learning in online learning environments. International Journal of Educational Leadership Preparation, 11(1), 89-119.

[10] Lee, J. (2014). An exploratory study of effective online learning: Assessing satisfaction levels of graduate students of mathematics education associated with human and design factors of an online course. The International Review of Research in Open and Distributed Learning, 15(1), 111-132.

[11] Mozelius, P., \& Hettiarachchi, E. (2017). Critical factors for implementing blended learning in higher education. International Journal of Information and Communication Technologies in Education, 6(1), 4-18.

[12] Naaj, M. A., Nachouki, M., \& Ankit, A. (2012). Evaluating student satisfaction with blended learning in a gender-segregated environment. Journal of Information Technology Education: Research, 11, 185-200.

[13] Nortvig, A. M., Petersen, A. K., \& Balle, S. H. (2018). A literature review of the factors influencing e-learning and blended learning in relation to learning outcome, student satisfaction and engagement. Electronic Journal of e-Learning, 16(1), 46-55.

[14] Rios, T., Elliott, M., \& Mandernach, B. J. (2018). Efficient instructional strategies for maximizing online student satisfaction. Journal of Educators Online, 15(3), n3.

[15] Sun, P. C., Tsai, R. J., Finger, G., Chen, Y. Y., \& Yeh, D. (2008). What drives a successful e-Learning? An empirical investigation of the critical factors influencing learner 
satisfaction. Computers \& Education, 50(4), 1183-1202.

[16] Umi, K.M., Nik, N. \& Nor Hazlin, .A. (2018). The underlying factors of learner readiness and satisfaction in blended learning environment. Proceedings of the IEEE 6th International Conference on MOOCs, Innovation and Technology in Education (MITE) 2018, 69-73.

[17] Van Alten, D. C., Phielix, C., Janssen, J., \& Kester, L. (2019). Effects of flipping the classroom on learning outcomes and satisfaction: A meta-analysis. Educational Research Review, 28, 1-18.

[18] Wu, J. H., Tennyson, R. D., \& Hsia, T. L. (2010). A study of student satisfaction in a blended e-learning system environment. Computers \& Education, 55(1), 155-164.

[19] Zhai, X., Gu, J., Liu, H., Liang, J. C., \& Chin-Chung, T. (2017). An experiential learning perspective on students' satisfaction model in a flipped classroom context. Journal of Educational Technology \& Society, 20(1), 198. 